\title{
The Seventh Grade Students' Generalization Strategies of Patterns
}

\author{
Mu'jizatin Fadiana', Siti M Amin², Agung Lukito ${ }^{3}$ \\ ${ }^{1}$ Department of Mathematics Education, Universitas PGRI Ronggolawe, Tuban, Indonesia \\ ${ }^{2,3}$ Department of Mathematics, Universitas Negeri Surabaya, Surabaya, Indonesia
}

\begin{tabular}{l}
\hline \hline Article Info \\
\hline Article history: \\
Received Feb 20, 2018 \\
Revised Apr 21, 2018 \\
Accepted Apr 24, 2018 \\
\hline
\end{tabular}

\section{Keywords:}

Pattern Generalization

Visualisation Strategies

\begin{abstract}
This article describes a generalization strategy on pictorial visual patterns. This explorative descriptive study involves 60 students of 7 Grade Student of private junior high school in Tuban East Java Indonesia. Data obtained through the pattern generalization task. The type of pattern used in this research is pictorial sequences with two non-consecutive terms. Selection of a pictorial sequences with two non-consecutive pattern to focus students' attention on visual stimuli. Based on the students answers of pattern generalization task, there are 33 students who answered correctly and 27 students answered wrong. From the correct answer, there are six different general formula representations. The visualization strategy used by the students begins by splitting the image into smaller elements. The way students break down into smaller elements is also diverse. Students divide the image in the form of $\mathrm{V}$ ( 2 matchsticks), $\mathrm{U}$ shape ( 3 matchsticks), square shape (4 matchsticks) and lastly divide in a unit additive consisting of 7 matchsticks.
\end{abstract}

Copyright $₫ 2018$ Institute of Advanced Engineering and Science. All rights reserved.

\section{Corresponding Author:}

Mu'jizatin Fadiana,

Departement of Mathematics Education,

Universitas PGRI Ronggolawe Tuban,

Manunggal street 61 Tuban, East Java, Indonesia.

Email: mujizatinfadiana@mhs.unesa.ac.id

\section{INTRODUCTION}

Mathematics is seen as the science of patterns and order [1] and looking for a pattern or regularity is one of the actions which are performed in mathematics on the whole [2]. Sandefur [3] states that patterns are the core of mathematics and language to express mathematics. While, in [4] describes mathematics as a systematic description and study of patterns. Not only is that, finding patterns one of the most important strategies for mathematics problems solving [5]. Cuoco [6] suggest that identifying patterns can foster critical thinking habits. And the pattern is also seen by some researchers as a way to develop algebraic thinking as it is a fundamental step to build generalizations, which is the essence of mathematics [2, 7].

Generalization is an important aspect in all areas of mathematics and is a competency that is concerned in learning mathematics at all levels. For example, in the arithmetic, the student can generalize that the multiplication of each integer by 5 will produce integers with the last digits 0 or 5 . In the geometry, the theorems in geometry can be regarded as the product of generalization [8]. Furthermore, generalization and formalization are intrinsic to mathematical activity and thinking [9].

Pattern Generalizations are interesting to examine because pattern generalizations can contribute to the development of problem-solving skills, through emphasis on analyzing specific cases, organizing data systematically, conjecturing and generalizing. Working with numerical, geometric and pictorial patterns can assist in building mathematical significance and contributing to the development of some skills related to 
problem solving and algebraic thinking $[10,11]$. In addition, generalizing geometric patterns can help develop students' visualization, reasoning and argumentation skills $[12,13]$.

Fadiana [14] states that the strategies students used in pattern generalizations are different. For numerical shapes, students use guessing, explicit and contextual strategies. While in generalizing the pictorial pattern, students use explicit and contextual strategies. This result is in line with the opinion of [15] who reported that the students were able to produce different ways of generalizing the pictorial pattern, in which the way students generalize due to the way the visualization is diverse. Especially for linear patterns, [5] identifies that there are several methods of completion that students use in a problem of linear patterns generalizations.

Number patterns presented as a sequence of pictorial terms have the potential to open up meaningful spaces for classroom exploration and discussion. However, despite the potential richness of such pictorial contexts, potentially meaningful pattern generalisation activities carried out in the classroom often become degraded to simple rote exercises in which the given pictorial sequence is simply reduced to an equivalent numeric sequence. $[16,17]$ argue that patterns in the context of images encourage students to build various generalizations. The type of pictorial pattern used in this study is a pattern with two consecutive nonconsecutive terms [18]. The reason for choosing a non-consecutive two-tier picture pattern is to focus students' attention on visual stimuli. This is supported by the research that has been done by [18]. Hershkowitz [19] also stated that pictorial patterns with two non-consecutive tribes are appropriate for encouraging generalization in an independent way and allowing students to use a variety of visual approaches.

Exploring information about student strategies in pattern generalizations and constructs of students 'thinking is important to be examined in order to develop students' algebraic thinking. This study aims to investigate the strategies used by the 7th Grade students of Junior High School in producing general formula (generalization) of the pictorial pattern with two non-consecutive terms.

\section{RESEARCH METHOD}

This is descriptive explorative research involving 60 students of one of the private Junior High School in Tuban, East Java, Indonesia. The subjects were the 7 th grade students, with the consideration that the students were in the early stage of formal operations, meaning they were able to consider different points of view simultaneously, to see the rules, and to think inductively as well to make hypotheses. The students were given task of pattern generalization. The subjects were selected based on their communication skills, which were easy to be interviewed and were able to express their thinking process.

This research uses two instruments, namely the main instrument and supporting instruments. The main instrument is the researcher, while the supporting instrument consists of audio visual recorder in the form of digital camera and tape recorder and pattern generalization task. The generalization task of the given pattern is as follows.

Look at the following diagrams containing squares and triangles built from matchsticks.
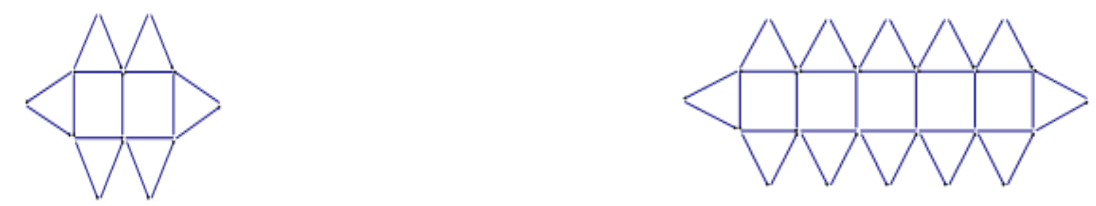

For 2 squares you need 19 matches For 5 squares you need 40 matches.

Give an algebraic "rule" or "formula" to work out the total number of matchsticks you will need if there are " $n$ " squares.

A descriptive analysis of students' performance was carried out by classifying the tstudents' answers on the pattern generalization tasks into correct and incorrect answers by considering a variety of types found in the students' answers. 


\section{RESULTS AND DISCUSSION}

\subsection{Result}

Based on the result of the assignment of pattern generalizations, there are 33 students who answered correctly, and 27 students answered incorrectly. From the correct answer, there are six general formulas representations. The diversity of answers generated by students is influenced by the variety of visual strategies students used. Here are the visual strategies and general formulas produced by students who answer correctly.

a) General formula $6 \mathrm{n}+(\mathrm{n}+1)+4$

With visual strategy, S1 divides the whole into smaller triangular units, V-shapes, and vertical matchsticks. The triangle is not visualized separately, but rather a pair placed vertically above and below. For the third pattern there are 3 pairs of triangles, each pair consisting of 6 matchsticks. So for the $n$-th pattern, there are $6 n$ matchstick and vertical $n+1$ matchstick. The shape of $V$ is fixed, there are 4 matchsticks. So overall, the generated general formula is $6 n+(n+1)+4$
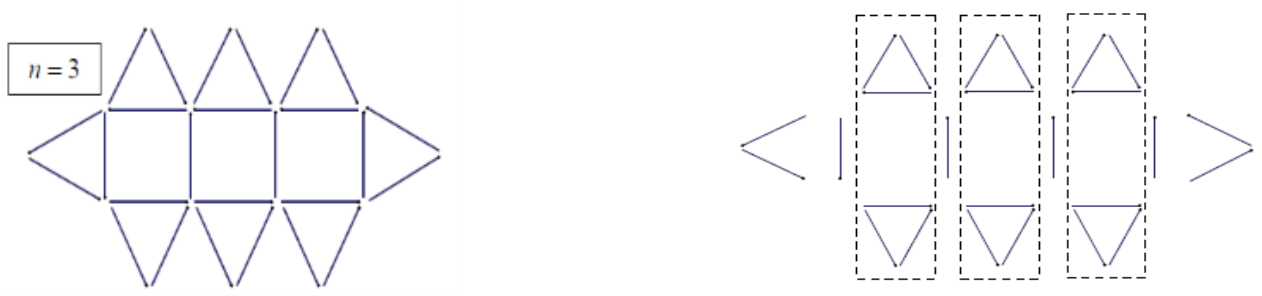

Figure 1. Visualization strategy of subject s1

b) General formula $[3(n-1)+4]+[2(2 n+2)]$

$\mathrm{S} 2$ divides the structure into square and triangle. The middle part of the pattern is subdivided into the initial square and a series of $U$ shapes on the side, each containing 3 matchsticks. S2 starts with the first 1 square consisting of 4 matchsticks. The next set of $U$ forms is (n-1) and each consists of 3 matchsticks. So the total of the middle part there are as many as $3(n-1)+4$ matchsticks. Then S2 completes the count of matching triangle matchsticks. For the square $n$, there are $2 n+2$ triangles, the upper triangle, the lower triangle, the right triangle, and the left triangle. Each triangle consists of two matchsticks. So many matching triangle matchsticks are $2(2 n+2)$. Overall, the resulting general formula is $[3(n-1)+4]+[2(2 n+2)]$.
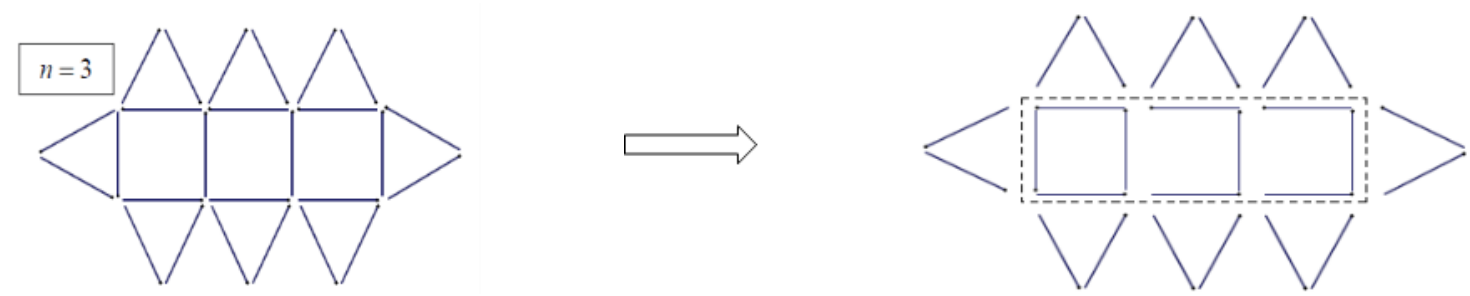

Figure 2. Visualization strategy of subject s2

c) General formula $(3 n+1)+4 n+4$

$\mathrm{S} 3$ visualizes the problem in a similar way to $\mathrm{S} 2$, but the approach is different, resulting in the general formula of different nth terms. S3 divides the structure into squares and triangles, but then divides the square into a vertical line followed by the $U$ shape side. So the whole square needs $3 n+1$ matchsticks. For the remaining structures, each square has two related triangles, one above and one below. Each pair of triangles (upper triangle and lower triangle) consists of 4 matchsticks. In addition, 4 matchsticks are required to complete the triangle at both ends. Thus many triangle-shaping matches are $4 n+4$, and overall the resulting general formula is $(3 n+1)+4 n+4$. 

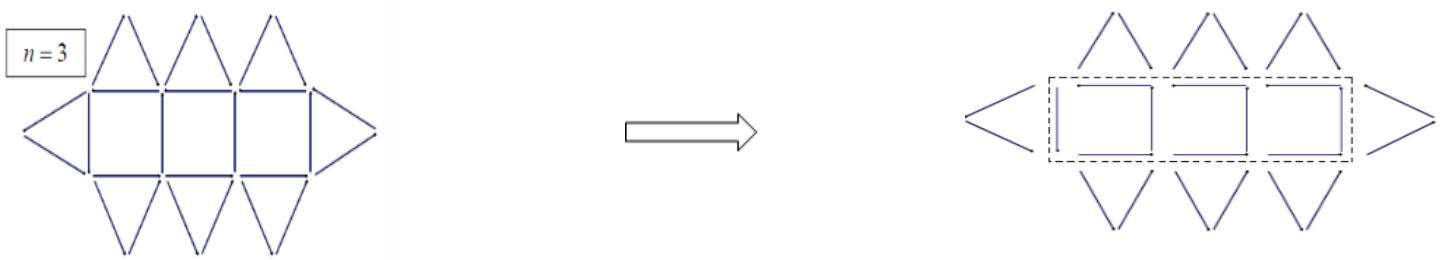

Figure 3. Visualization strategy of subject s3

d) General formula $4 n+3 n+5$

The visualization strategy used by S4 is by dividing the structure into squares and triangles. In the square section, S4 excludes 1 matchstick from the square. So that the square part only consists of $U$ shape side. Many matchsticks that make up the $U$ side as a whole are $3 n$. For the remaining structures, each square has two related triangles, one above and one below. Each pair of triangles (upper triangle and lower triangle) consists of 4 matchsticks. In addition, there are 3 matchsticks on the left side triangle and 2 matchsticks on the right side triangle. Thus many triangle-shaping matches are $4 n+5$, and as a whole the resulting general formula is $3 n+4 n+5$.
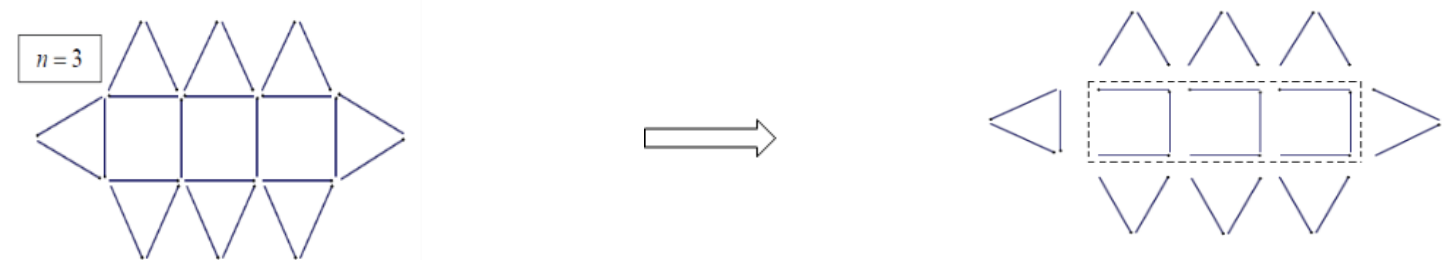

Figure 4. Visualization strategy of subject s4

e) General formula $3 n+3 n+6+n-1$

S5 divides the whole structure into two distinct component parts, namely triangles and vertical lines. 1 square, consisting of 2 related triangles, the upper triangle and the lower triangle. Each triangle consists of 3 matchsticks. So many matches of upper and lower triangle matches for $n$-square are $3 n+3 n$. The right side and left side of each there is 1 triangle, so there are 6 matchsticks. The vertical line as much as $n-1$. Thus the overall general formula produced is $3 n+4 n+5$.
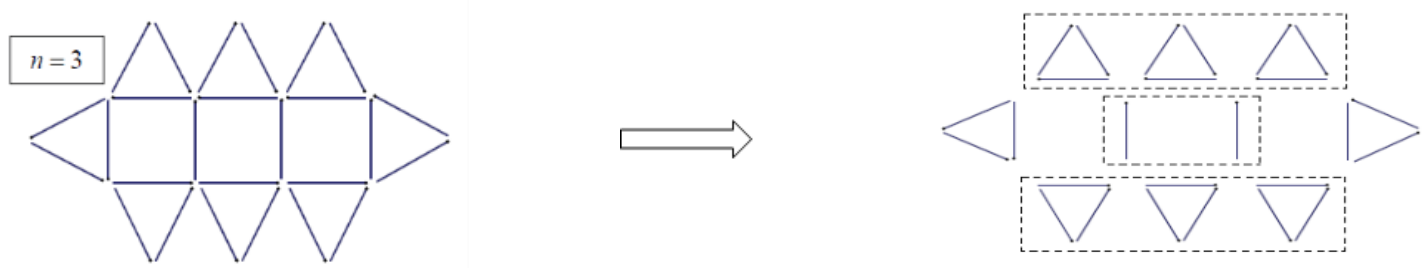

Figure 5. Visualization strategy of subject s5

\section{f) General Formula General formula $7 n+5$}

S6 divides the structure into a V shape on one side and 1 triangle on the other, and the remainder to additive 7 pairs, that is, the effective base unit is inserted into the structure to advance from one tribe to the next. Overall the generated general formula is $7 n+5$. 

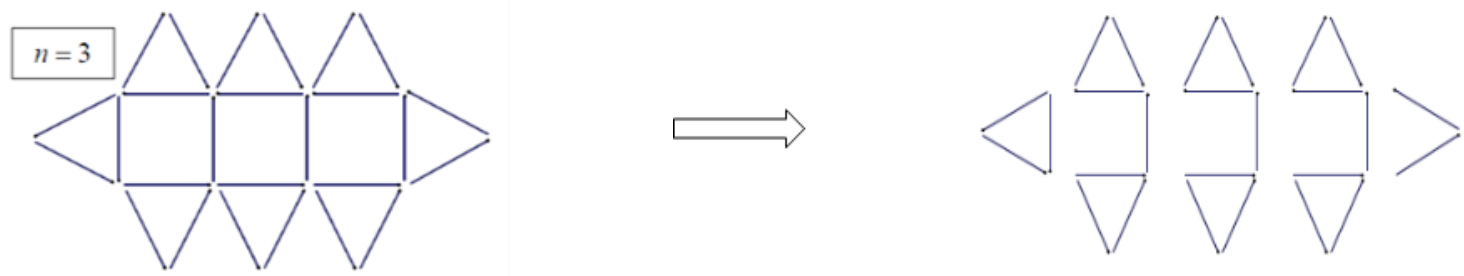

Figure 6. Visualization strategy of subject s6

\subsection{Discussion}

Different visualization strategies can be seen in the diversity of student responses. The visualization strategy used by students in performing generalization tasks is influenced by students' visual reasoning. Visualisation as both the product and process of creating, interpreting and reflecting upon images, is gaining increased focus in the fields of both mathematics and mathematics education [20-21]. The visualization strategy begins by splitting the whole image into smaller parts. It can be seen that the students divide the image in the form of V (2 matchsticks), U shape (3 matchsticks), square shape (4 matchsticks) and lastly divide in a sum unit consisting of 7 matchsticks. After being separated into several components, the visualization process is continued by multiplying the various parts by the number of numbers each also by adding them with constants. So obtained general formula. [16] uncovered various "mechanisms" of visualisation in the building of a mathematical generalisation in a pictorial context. They distilled the various visual strategies into the following analytical components: (a) decomposition of a structure into smaller substructures and units, (b) creation of auxiliary constructions, (c) transformation of the whole structure into a different configuration, and (d) recomposition and synthesis. Their results led [16] to propose that visualization can be far more than the intuitive support of higher level reasoning, in that it may well constitute "the essence of rigorous mathematics" [16].

Visualization plays an important role for students in the arrangement of algebraic (symbolic) representations of the general formula. Patterns represented in drawings help students to use different visualization strategies. However, for students who have numerical thinking tendencies, visualization strategies are not widely used in generating general formulas. Students will use the table and look for possible relationships between dependent variables and independent variables in determining general formula.

In this study, most of the students achieved to recognize the relationships between terms and obtain the general formulas of the patterns. However, some of them weren't able to make generalization. Many researchers indicate that students more successful in the pattern problems which they are familiar [2] [17] [22]. Due to that 7th grade students are familiar to linear patterns and this type is appropriate in terms of students`cognitive levels most of students might be successful in making correct generalization in this study.

\section{CONCLUSION}

Based on the result of the research, it can be concluded that pictorial sequences with two nonconsecutive terms can encourage students' visual reasoning. Visual reasoning affects students' visualization strategies. Different visualization strategies result in generalization products in the form of different general formulas. So that visualization has an important role in arrangement of student algebra representation.

The visualization strategy used by the students begins by splitting the image into smaller elements. The division into smaller elements helps students to capture the regularity of both known images. The way students break down into smaller elements is also diverse. Students divide the image in the form of V ( 2 matchsticks), U shape (3 matchsticks), square shape (4 matchsticks) and lastly divide in a sum unit consisting of 7 matchsticks. So from this research there are 6 different strategies used by research subjects. Different strategies result in differences in the symbolic algebraic representation of the general formula.

We hope that further researchers who are interested in studying generalizations can continue and reinforce the results of this research by involving subjects depend on logical thinking levels (concrete operational stage, transitional stage or formal operational stage). In addition to expanding the subjects of research, it is also expected that further works can implement research with different instruments, such as using diverse pattern image variations. Research on pattern generalization should be developed more broadly as a means to improve and enhance students' algebraic thinking. 


\section{ACKNOWLEDGEMENTS}

We acknowledged RISTEK - DIKTI for grant in aid Penelitian Disertasi Doktor (PDD) for supporting and funding this study.

\section{REFERENCES}

[1]. L.A. Steen, “The Science of Patterns.” Science, New Series, 240, pp 611-616, 1988.

[2]. J. Orton, A. Orton, and T.Roper, "Pictorial and Practical Contexts and the Perception of Pattern", In Pattern in the Teaching and Learning of Mathematics, 1999, pp. 121-136.

[3]. J. Sandefur, J and D. Camp, "Patterns: Revitalizing Recurring Themes in School Mathematics", Mathematics Teacher., 98(4), pp 211, 2004.

[4]. G.A. Goldin, "Representation in Mathematical Learning and Problem Solving," In Handbook of International Research in Mathematics Education, ed MahwahNJ: Erlbaum, 2002, pp 197-218.

[5]. K. Stacey, "Finding and using patterns in linear generalising problems". Educational Studies in Mathematics, 20, pp 147-164, 1989.

A. Cuoco, E.P. Goldenberg, and J. Mark, J, "Habits of Mind: An Organizing Principle for Mathematics Curricula", Journal of Mathematical Behaviour, 15, 375-402, 1996.

[6]. R. Zazkis, and P. Liljedahl, "Generalization of patterns: The Tension Between Algebraic Thinking and Algebraic Notation", Educational Studies in Mathematics., 49, pp 379-402, 2002.

[7]. J. Mason, "Expressing generality and roots of algebra", In Approaches to algebra, ed Dordrecht: Kluwer, 1996, pp $65-86$.

[8]. J.J Kaput, “Teaching and Learning a New Algebra”, In Mathematics Classrooms that Promote Understanding, ed Mahwah, NJ: Lawrence Erlbaum Associates, Inc, 1999, pp 133-155.

[9]. NCTM., "Principles and Standards for School Mathematics", Reston, VA: NCTM, 2000.

[10]. Vale, A. Barbosa, A. Borralho,I. Cabrita, L. Fonseca, \& et. al. "Padrões no Ensino e Aprendizagem da Matemática: Propostas curriculares para o ensino básico"., Viana do Castelo: ESEVC, 2009.

[11]. L. Healy, and C. Hoyles, "Seeing, doing and expressing: An evaluation of task sequences for supporting algebraic thinking". Proceedings of the 20th International Conference of the International Group for the Psychology of Mathematics Education., Valencia, Spain, Vol. 3, pp 67-74, 1996.

[12]. N. Presmeg, "Research on visualization in learning and teaching mathematics: Emergence from psychology", In Handbook of research on the psychology of mathematics education, ed Dordrecht: Sense Publishers, 2006, pp 205235.

[13]. M. Fadiana, "Strategi Generalisasi Pola Siswa SMP Kelas VII". Prosiding Seminar Nasional Matematika X Tahun 2016. Semarang : FMIPA Universitas Negeri Semarang, 2016.

[14]. E. Waren, "Young Children's Ability to generalise the Pattern Rule for Growing Patterns", 2005. In Proceedings of the 29 Conference of the International Group for the Psychology of Mathematics Education, ed Melbourne: PME. Vol. 4, pp 305-312, 2005.

[15]. Hershkowitz, R., Arcavi, A., \& Bruckheimer, M., "Reflections on the status and nature of visual reasoning - the case of the matches". International Journal of Mathematical Education in Science and Technology, 32(2), 255-265, 2001.

[16]. J.K. Lannin, "Developing Mathematical Power by Using Explicit and Recursive Reasoning", Mathematics Teacher, 98(4), pp 216-223, 2004.

[17]. D. Samson, "Number Patterns, Cautionary Tales and the Calculus of Finite Differences", Learning and Teaching Mathematics, 3, 3-8, 2006.

[18]. R. Hershkowitz, T. Dreyfus, D. Ben-Zvi, A. Friedlander, N. Hadas, T. Resnick, et al, "Mathematics Curriculum Development for Computerised Environments: A Designer-Researcher-Teacher-Learner Activity", In Handbook of International Research in Mathematics Education, ed Mahwah, NJ: Lawrence Erlbaum Associates, 2002, pp 657694.

[19]. W. Zimmermann, and S. Cunningham, "Editors' Introduction: What is Mathematical Visualization?", In Visualization in Teaching and Learning Mathematics, ed Washington: Mathematical Association of America, 1991, pp 1-8.

[20]. Arcavi, "The Role of Visual Representations in the Learning of Mathematics", Educational Studies in Mathematics, 52, 215-241, 2003.

[21]. Y. Feifei, Y, "Diagnostic Assessment of Urban Middle School Student Learning of Pre algebra Patterns", Doctoral Dissertation, Ohio State University: USA, 2005. 


\section{BIOGRAPHIES OF AUTHORS}

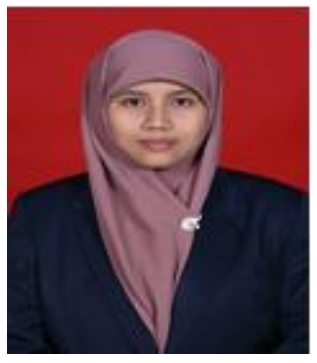

Mu'jizatin Fadiana is a lecturer in Mathematics Education Program Faculty of Teacher Training and Education, Universitas PGRI Ronggolawe, Tuban, East Java, Indonesia. She is currently studying a doctoral program at Universitas Negeri Surabaya, East Java, Indonesia majoring in mathematics education. She was interested research about mathematical embodiment and writing the dissertation about pattern generalization based on semiotic perspectives.

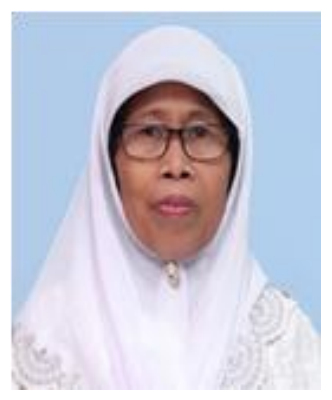

Siti M Amin is a professor in mathematic education. She is a head of doctoral mathematic education program at Universitas Negeri Surabaya. She is an active researcher in field of mathematic education, include curriculum development, teaching and learning, educational evaluation, teacher development, educational management and leadership. He has conducted many researches in mathematic education. She has also authored many books in mathematic education and education, and has written several articles of journals on the topics.

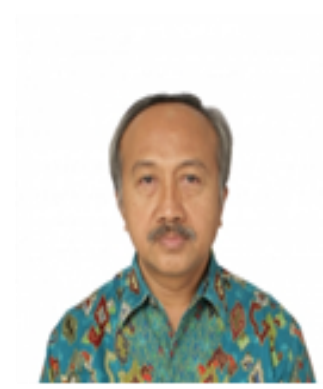

Agung Lukito is a doctor in mathematic. He is a lecture in Department of Mathematic, Faculty of Mathematics and Natural Science, Universitas Negeri Surabaya, Surabaya, East Java, Indonesia. He is an active researcher in field of mathematic and mathematic education. He has conducted many researches in mathematic, mathematic education, curriculum development, teaching and learning, and the others. In addition, he has an authored and also an editor in many books in mathematic education, and has written several articles of journals on the topics. 